\title{
Context availability and the recall of abstract and concrete words
}

\author{
PAULA J. SCHWANENFLUGEL, CAROLYN AKIN, and WEI-MING LUH \\ University of Georgia, Athens, Georgia
}

\begin{abstract}
Predictions of an automatic-imagery, strategic-imagery, and context-availability hypothesis of concreteness effects in free recall were examined. In each experiment, recall of abstract and concrete words controlled for rated context availability was compared with the typical situation in which context availability is confounded with imageability. In Experiment 1, a directed intentionalrecall task produced concreteness effects in recall. Experiment 2 compared concreteness effects in recall following three orienting tasks: imagery rating, context-availability rating, and a directed intentional-memory task. Concreteness effects in the context-availability-controlled condition were found following the imagery-rating and the directed intentional-memory tasks, but not after the context-availability-rating task. In Experiment 3, subjects reported the strategies that they used to encode the list. Subjects reporting an imagery strategy showed concreteness effects for words controlled for rated context availability, but those not reporting it did not. These results support a strategic-imagery view of concreteness effects in free recall.
\end{abstract}

There is now a long history to the general finding that abstract verbal materials are remembered more poorly than concrete materials (see Paivio, 1971, 1986). For example, this finding has been shown in studies of paired associates learning (Paivio, 1965), memory for sentences (Brewer, 1975; Marschark \& Paivio, 1977), and free recall of unrelated word lists (Christian, Bickley, Tarka, \& Clayton, 1978; Rubin, 1980; Rubin \& Friendly, 1986), among others. Abstract words are remembered more poorly by children and adults alike (Vellutino \& Scanlon, 1985). Stimulus concreteness or, to be more precise, stimulus imageability is one of the most powerful predictors of recall in studies of verbal memory (Rubin, 1983). However, the causal role of imagery in these studies of concreteness effects in verbal memory have been the source of much debate. In this article, we will discuss the emergent predictions of three hypotheses for why abstract words are remembered more poorly than concrete words.

The first hypothesis, which we will call the automaticimagery hypothesis, is designed to represent the intuitive view that the sensory information associated with concrete words naturally makes them more resistant to forgetting. This view claims that there are two representational systems associated with concepts in semantic memory: a verbal representation (consisting of verbal associates) and an

Preparation of this article was supported in part by Grant BNS- 8808453 from the National Science Foundation to the first author. We appreciate the helpful comments that W. Fabricius, R. Fisher, M. Marschark, A. Paivio, and E. Shoben gave us on an earlier version of this paper. Some of the research described in this article was presented at the Southeastem Psychological Association meeting in March 1987. C. Akin is now affiliated with the Banks County, GA, Public School System. Correspondence should be addressed to $P$. J. Schwanenflugel, Department of Educational Psychology, or the Institute for Behavioral Research, 325 Aderhold Hall, University of Georgia, Athens, GA 30602. imaginal representation (consisting of images), which are differentially available in memory tasks, depending on the concreteness of the verbal materials. This hypothesis postulates that the imaginal code becomes invoked automatically and obligatorily in all verbal memory tasks in which potentially imageable materials are used, because the images form an inalienable part of their semantic representations. According to this intuitive view, the automatic availability of an imaginal code for concrete verbal materials enables them to be recalled better than abstract materials, because they have another means through which they can be stored and retrieved. Ratings of imageability might be considered to be a measure of the automaticity with which imagery can be invoked in a given task. This hypothesis is typically associated with Paivio (1971), but it is not the version to which he subscribes (see Paivio, 1986). The predictions of this hypothesis are also more circumscribed than those associated with Paivio's $(1971,1986)$ theory, because it makes no particular claims about the types of errors in recall that can be expected on the basis of the availability of the two codes.

The second hypothesis, which we will call the strategicimagery hypothesis, is a weak version of the theory described above. This theory claims that imagery is not automatically accessed as a function of the degree of concreteness of the verbal stimuli. Instead, imagery is invoked strategically by persons when they see imagery as being helpful toward meeting the goals of a task. Thus, in directed memory tasks typical of verbal learning studies (such as recalling lists of unrelated words), persons are likely to see imagery as being particularly useful. When persons see other options as being more useful or when they are prevented from using imagery, concreteness effects attributable to imagery should disappear. Ratings of imagery, then, serve to reflect the availability of strategic 
imagery when other strategies are not seen as useful. Several versions of this strategic-imagery hypothesis have been proposed (e.g., Paivio, 1986).

A third hypothesis, which we will call the contextavailability hypothesis (Bransford \& McCarrell, 1974; Kieras, 1978; Schwanenflugel, 1991; Schwanenflugel, Harnishfeger, \& Stowe, 1988; Schwanenflugel \& Shoben, 1983; Wattenmaker \& Shoben, 1987) emphasizes the availability of information from prior knowledge to explain concreteness effects. Successful comprehension and later recall are said to be a reflection of the ability of the person to relate the to-be-remembered materials to the contextual information present in the person's knowledge base. Abstract verbal materials are said to be more poorly comprehended and, therefore, poorly recalled, because people experience greater difficulty in accessing the relevant world knowledge necessary for understanding such materials. Therefore, abstract materials are recalled more poorly than concrete materials, not because of the lesser availability of imagery, but because of the availability of associated contextual information in memory for such materials.

The context-availability hypothesis predicts that presentation of abstract and concrete verbal materials in a supportive context will result in equivalent comprehension and recall by increasing the availability of relevant contextual information from prior knowledge. Several studies have shown that presenting abstract sentences in supportive contexts will eliminate the difference between abstract and concrete sentences in comprehension time (Schwanenflugel \& Shoben, 1983) and recall (Marschark, 1985; Wattenmaker \& Shoben, 1987). Similarly, concreteness effects in cued-recall studies have been found to disappear when the abstract or concrete stimulus words were meaningfully related to their response words (Bransford \& McCarrell, 1974; Peterson, 1974). Also, presentation of abstract and concrete words in a supportive sentence context has been shown to eliminate differences between word types in lexical decision (Schwanenflugel et al., 1988; Schwanenflugel \& Shoben, 1983), naming (Schwanenflugel \& Stowe, 1989), and sentence-meaningfulness judgment times (Schwanenflugel \& Stowe, 1989).

This hypothesis also predicts that ratings of the ease with which contextual information can be retrieved from prior knowledge should be more predictive of comprehension for isolated abstract and concrete words than should ratings of imageability. In support of this prediction, Schwanenflugel et al. (1988) found similar lexical decision times for abstract and concrete words controlled for rated context availability but varying in rated imageability. Faster lexical decision times for concrete than for abstract words were found only when rated context availability was confounded with imageability. This relationship between contextavailability ratings and lexical decision times remained significant even when the influence of imageability was statistically controlled.
While suggestive of the importance of context availability in verbal comprehension and memory, the studies do not necessarily imply that imagery is never used by persons independently of the retrievability of prior contextual knowledge. Strong concreteness effects are almost invariably displayed in memory studies done with unrelated verbal materials, such as typical studies of paired associates learning (e.g., Paivio, 1965) or word list recall (Christian, et al., 1978). Although these concreteness effects may be a simple reflection of the generally lower retrievability of contextual information from prior knowledge for abstract words, it is possible that the concreteness effects are at least partially attributable to imagery.

The purpose of the present study was to determine whether imageability has an effect on the recall of abstract and concrete words that is independent of the accessibility of contextual information from prior knowledge. In three experiments, subjects were asked to recall lists of unrelated abstract and concrete words controlled for rated context availability. With accessibility of prior contextual knowledge controlled, the viability of differential predictions of the automatic-imagery, strategic-imagery, and context-availability hypotheses of concreteness effects in memory could be compared.

\section{EXPERIMENT 1}

The first experiment compared a situation in which the rated context availability of abstract and concrete concepts was controlled for with one in which context availability was confounded with concreteness (as is usually the case in studies of this type). Ratings of context availability were used as indices of the ease with which information from prior knowledge could be accessed for each word. Specifically, in such ratings, people are asked to rate the ease with which they can think of a context or circumstance associated with the word or in which the word could appear. Ratings of imageability were used as indices of the ease with which imagery could be experienced for each word. In the controlled condition, abstract and concrete words were chosen that were rated as being equivalent in the ease with which persons could retrieve contextual information from prior knowledge but for which abstract words were rated as being less concrete and imageable. In the confounded condition, abstract and concrete words differed on ratings of context availability, concreteness, and imageability. Therefore, if a strict context-availability view is correct, it would be expected that free recall should reflect context-availability ratings and persons would display concreteness effects only when context availability and concreteness are confounded. If, however, imageability is identifiable as being somehow separate from context availability (as for the automatic- or strategic-imagery hypotheses), it would be expected that concreteness effects would be detectable regardless of whether rated context availability was controlled or confounded with concreteness. 


\section{Method}

Design. A 2 (concreteness: abstract vs. concrete) $\times 2$ (contextavailability relation: controlled vs. confounded with concreteness) design was used. Concreteness was a within-subject variable, and context availability relation was a between-subject variable.

Stimuli. The stimuli used in the present Experiment 1 were derived from a set of norms developed by Schwanenflugel et al. (1988) and used in Experiment 1 of that study. The characteristics of these stimulus words can be seen in Table 1 . These items consisted of a set of abstract and concrete words for which rated context availability was controlled and another set for which rated context availability and concreteness were confounded. There were 28 abstract and 28 concrete words in each set. For the context-availabilitycontrolled condition, the concrete words were rated as being higher than the abstract words in concreteness and imageability (both $p s<.05$ ), but not differing in rated context availability (see Schwanenflugel et al., 1988, for context-availability instructions), word frequency (as defined by Francis \& Kucera, 1982), or number of single associates generated by 50 subjects (all $p s>.20$ ). For the context-availability-confounded condition, the concrete words were rated as being higher than the abstract words in rated concreteness, imageability, number of associates, and context availability (all $p s<.05$ ), but not in word frequency $(p>.20)$. Also, across context-availability conditions, the abstract and concrete words were rated as being similarly concrete and imageable (both $p s>.20$ ). (For each of the above comparisons, significance was determined on the basis of a $t$ test.)

From these 112 words, 16 lists of 14 words each were constructed so that each list contained words from either the context-availabilitycontrolled condition or the confounded condition. The words were arranged on the lists so that if an abstract word appeared in a particular position on one list, a corresponding concrete word appeared in the same position on another list. Each word appeared on two lists; if the word appeared toward either end of one of the lists, it appeared toward the middle of the other. This was done to minimize serial position and intralist association effects for any given word within a list.

Procedure. Subjects were run in groups of up to 5 at a time. They were asked to remember a list of words that would be read to them. They were told that there would be a warm-up trial followed by an experimental list, but that, after the experimental list was read to them, instead of recalling the list they were to complete a paced vocabulary test for $15 \mathrm{~min}$ first. They were told that this would be followed by recall of the experimental list. The word list was read to them at a rate of one word every $5 \mathrm{sec}$. The vocabulary items were from the Nelson-Denny Reading Test vocabulary subtest (Brown, Bennett, \& Hanna, 1981) and were presented one item every $9 \mathrm{sec}$ on a screen in the laboratory. They were told not to rehearse the memory items during the vocabulary test. After completing this test, the subjects were told to recall the experimental list in any order.
Subjects. Eighty students from an introductory level psychology or educational psychology class participated as subjects for class credit.

\section{Results and Discussion}

A subject was given credit for recalling a particular item if the item recalled was a semantically close inflectional variant of the target word (e.g., alcohol $\rightarrow$ alcoholic; mistake $\rightarrow$ mistakes). That is, the relationship between the recalled word and the list word was semantically transparent, given knowledge of inflectional rules (see Nagy \& Anderson, 1984). The words that were not credited were of the following two types: (1) words that were not inflectional variants of target words but could be considered synonyms of list items (only $4 \%$ of total words recalled), and (2) words that neither appeared on the list nor resembled the meanings of the list words $(11 \%$ of total words recalled).

Mean percent recall for each condition can be seen in Table 2. To examine whether concreteness effects in free recall were either reduced or eliminated when rated context availability was controlled, a 2 (concreteness) $\times 2$ (contextavailability relation) analysis of variance (ANOVA) was performed. This analysis yielded a significant effect of concreteness $\left[F(1,78)=37.31, M S_{\mathrm{e}}=264, p<.05\right]$, but not of context-availability relation $\left(F<1, M S_{\mathrm{e}}=\right.$ 267). Of particular importance, the main effect of concreteness was not qualified by a significant interaction between concreteness and context-availability relation $\left[F(1,78)=1.98, M S_{c}=264, p>.10\right]$. Further planned comparisons demonstrated a significant effect of concreteness in both the context-availability-controlled condition $(p<.05)$ and the context-availability-confounded condition $(p<.05)$. Thus, it appears that even when rated context availability is controlled, recall is better for concrete words than for abstract words.

The pattern of recall across conditions in Experiment 1 causes problems for a context-availability view of concreteness effects. In particular, this hypothesis predicts that when the accessibility of contextual information from prior knowledge is controlled, there should be no concreteness effects in recall. In conflict with this prediction, a significant $12.1 \%$ superiority in recall was demonstrated for concrete words relative to abstract words when context

Table 1

Attributes of the Words Used in the Experiments

\begin{tabular}{|c|c|c|c|c|c|c|c|c|}
\hline \multirow[b]{4}{*}{ Attribute } & \multicolumn{8}{|c|}{ Relation of Context Availability to Concreteness } \\
\hline & \multicolumn{4}{|c|}{ Controlled } & \multicolumn{4}{|c|}{ Confounded } \\
\hline & \multicolumn{2}{|c|}{ Concrete } & \multicolumn{2}{|c|}{ Abstract } & \multicolumn{2}{|c|}{ Concrete } & \multicolumn{2}{|c|}{ Abstract } \\
\hline & $\boldsymbol{M}$ & $S D$ & $M$ & $S D$ & $M$ & $S D$ & $M$ & $S D$ \\
\hline $\begin{array}{l}\text { Context availability* } \\
\text { Concreteness* } \\
\text { Imageability* }\end{array}$ & $\begin{array}{l}5.29 \\
6.16 \\
6.23\end{array}$ & $\begin{array}{l}.29 \\
.39 \\
.43\end{array}$ & $\begin{array}{l}5.22 \\
2.65 \\
2.40\end{array}$ & $\begin{array}{l}.31 \\
.52 \\
.56\end{array}$ & $\begin{array}{l}6.15 \\
6.15 \\
6.16\end{array}$ & $\begin{array}{l}.26 \\
.55 \\
.30\end{array}$ & $\begin{array}{l}4.17 \\
2.45 \\
2.44\end{array}$ & $\begin{array}{l}.22 \\
.69 \\
.43\end{array}$ \\
\hline $\begin{array}{l}\text { Word frequency } \\
\text { Number of associates }\end{array}$ & $\begin{array}{c}58 \\
22.9\end{array}$ & $\begin{array}{l}61 \\
7.3\end{array}$ & $\begin{array}{c}75 \\
22.8\end{array}$ & $\begin{array}{l}60 \\
5.5\end{array}$ & $\begin{array}{c}73 \\
22.5\end{array}$ & $\begin{array}{l}67 \\
5.0\end{array}$ & $\begin{array}{c}77 \\
27.6\end{array}$ & $\begin{array}{l}55 \\
6.8\end{array}$ \\
\hline
\end{tabular}

*Ratings were on a 1-7, scale with 7 representing the positive end of the scale. 
Table 2

Mean Percent Recall for Experiment 1

\begin{tabular}{ccc} 
Relation of Context & \multicolumn{2}{c}{ Concreteness } \\
\cline { 2 - 3 } Availability to Concreteness & Abstract & Concrete \\
\hline Controlled & 20.1 & 32.2 \\
Confounded & 19.6 & 38.9 \\
\hline
\end{tabular}

availability was controlled. The concreteness effects in each of the context-availability conditions, then, seem to be more specifically attributable to the imageability of the words than to the availability of contextual information.

\section{EXPERIMENT 2}

Although the finding of concreteness effects in both context-availability conditions appeared to indicate the operation of imagery in memory for the word lists, it is unclear whether the use of imagery in Experiment 1 was an automatic function of the concreteness of the individual words on the lists (as predicted by the automatic-imagery hypothesis described earlier) or whether imagery was employed strategically by subjects to learn the lists (as predicted by the strategic-imagery hypothesis). If the use of imagery is strategic, it should be possible to interfere with the implementation of imagery strategies by asking subjects to perform operations on the word lists that do not invoke imagery. One way to accomplish this is to control the activities that subjects engage in to encode the word lists by employing incidental rather than intentional recall following various encoding operations. Specifically, in Experiment 2, subjects were asked to perform one of three different orienting tasks: (1) an imagery-rating orienting task, (2) a context-availability-rating orienting task, or (3) a task with directed intentional-memory instructions. This last condition was designed to provide a baseline from which to compare the influence of the two incidental-recall tasks on recall. It also served to ensure that the findings of Experiment 1 could be replicated when small changes in procedure were made.

Of particular interest to the automatic- and strategicimagery views of concreteness effects is recall of abstract and concrete words controlled a priori for rated context availability. If imagery is an automatic aspect of encoding concrete materials, concreteness effects should be present even when subjects have performed the contextavailability orienting task. If imagery is strategic, concreteness effects in recall should be present only following the imagery orienting and directed intentional-memory tasks, but not the context-availability orienting task.

\section{Method}

Design. A 2 (concreteness: abstract vs. concrete) $\times 2$ (contextavailability relation: controlled vs. confounded) $\times 3$ (orienting task: context-availability-rating, imagery rating, or no-orienting task) design was used. In this experiment, both concreteness and contextavailability relation were within-subject factors, whereas orienting task was a between-subject factor.

Stimuli and Procedure. The stimuli were the same as those in Experiment 1, with the following exceptions: (1) List length was increased. Subjects received word lists consisting of 28 rather than 14 words, with 7 words from each condition. (2) A particular word appeared on only one word list. Therefore, a given subject received one of four possible lists.

Subjects participated in one of three orienting-task conditions. In the context-availability orienting-task condition, subjects were given context-availability-rating instructions (Schwanenflugel at al., 1988) and told that a list of words would be read to them, one word every $5 \mathrm{sec}$. They were told that during that 5 -sec interval they would have to rate the word on the ease with which they could think of a context or circumstance associated with the word. No mention was made of their later free recall. In the imagery-rating orientingtask condition, subjects read the imagery instructions used by Paivio, Yuille, and Madigan (1968). Otherwise, the procedure was similar to that used in the context-availability orienting-task condition. In the no-orienting-task condition, subjects were simply told to try to memorize the words read to them in any manner they chose during the 5 sec between words. In all conditions, subjects were told to recall the list immediately after the list was read to them.

Subjects. Ninety-six students from an introductory psychology class participated in this experiment to fulfill a class requirement. Thirty-two subjects participated in each orienting-task condition.

\section{Results and Discussion}

Recall scores were calculated as in Experiment 1. Of the words recalled by the subjects, $.5 \%$ were words that could be considered synonyms and another $3.9 \%$ were words that were neither from the list nor synonymous with list words. As before, such words were not credited toward a subject's recall. Mean percent recall for each orienting-task condition can be seen in Table 3.

To determine whether there were differential effects of concreteness as a function of orienting task and contextavailability relation, a 2 (concreteness) $\times 2$ (contextavailability relation) $\times 3$ (orienting task) ANOVA was performed. This analysis yielded a significant main effect of concreteness $\left[F(1,93)=37.71, M S_{e}=309, p<\right.$ $.05]$, but not of context-availability relation or orienting task $\left[F<1, M S_{\mathrm{e}}=350\right.$, and $F(2,93)=1.04, M S_{\mathrm{e}}=$ 473 , both $p s>.10$ ]. This analysis also yielded a significant two-way interaction between context-availability relation and concreteness $\left[F(1,93)=9.33, M S_{c}=263\right.$, $p<.05$ ], suggesting that concreteriess effects were somewhat smaller when context availability was controlled for than when it was not. There were marginally significant interactions between concreteness and orienting task $\left[F(2,93)=2.90, M S_{\mathrm{e}}=309, p<.10\right]$ and between context-availability relation and orienting task $[F(2,93)$ $=2.63, M S_{\mathrm{e}}=350, p<.10$ ]. Most importantly, a marginally significant three-way interaction between concreteness, context-availability relation, and orienting task was found $\left[F(2,93)=2.48, M S_{c}=264, p<.10\right]$. The form

Table 3

Mean Percent Recall for Experimeat 2

\begin{tabular}{|c|c|c|c|c|}
\hline \multirow[b]{3}{*}{ Orienting task } & \multicolumn{4}{|c|}{$\begin{array}{c}\text { Relation of Context Availability } \\
\text { to Concreteness }\end{array}$} \\
\hline & \multicolumn{2}{|c|}{ Controlled } & \multicolumn{2}{|c|}{ Confounded } \\
\hline & Abstract & Concrete & Abstract & Concrete \\
\hline Context availability & 33.9 & 29.9 & 29.5 & 43.3 \\
\hline Imageability & 30.4 & 39.3 & 26.3 & 48.2 \\
\hline None & 34.8 & 47.3 & 29.0 & 41.5 \\
\hline
\end{tabular}


of this interaction appeared to indicate that the orienting tasks differentially influenced the recall of abstract and concrete words particularly when context availability was controlled.

If the orienting tasks differentially influenced the degree to which concreteness effects were present in recall, it should be particularly evident in the context-availabilitycontrolled condition. Therefore, the context-availabilitycontrolled conditions were analyzed separately from the context-availability-confounded condition. A 2 (concreteness) $\times 3$ (orienting task) ANOVA performed on recall for words in the context-availability-controlled condition yielded a significant effect of concreteness $[F(1,93)=$ $\left.5.98, M S_{\mathrm{e}}=284, p<.05\right]$ and a marginal effect of orienting task $\left[F(2,93)=2.98, M S_{c}=452, p<.10\right]$. More importantly, however, there was a significant interaction between concreteness and orienting task $[F(2,93)$ $=4.01, M S_{c}=284, p<.05$ ], showing that orienting task had a differential influence on the size of the concreteness effect displayed for those items.

Further planned comparisons for recall of words in the context-availability-controlled condition were performed to test for the presence or absence of concreteness effects in the various orienting tasks. These showed a significant concreteness effect for the imagery-rating orienting task and the intentional-recall task (both $p s<.05$ ), but not for the context-availability orienting task $(p>.10)$. Further complex contrasts showed that the concreteness effects were similar for the imagery and intentional-recall tasks $[t(124)=.59, p>.10]$. However, the contextavailability orienting task displayed smaller concreteness effects than did either the imagery-rating orienting-task $[t(124)=2.02, p<.05]$, or the no-orienting-task condition $[t(124)=2.61, p<.05]$. Therefore, these analyses support the finding of the larger ANOVA that the various orienting tasks had a substantial influence on the presence or absence of concreteness effects in recall.

The words in the context-availability-confounded condition represent the usual case in studies of concreteness effects in memory. Given that correlation between imageability and context availability has been shown to be greater than .70 in several studies (Schwanenflugel et al., 1988; Schwanenflugel \& Shoben, 1983), it would be very difficult to detect any differential effects of imagery in studies of this type unless context availability was explicitly controlled. As anticipated, a 2 (concreteness) $\times$ 3 (orienting task) ANOVA for words in the contextavailability-confounded condition yielded a significant main effect of concreteness $\left[F(1,93)=43.06, M S_{\mathrm{c}}=\right.$ $288, p<.05$ ], a nonsignificant main effect of orienting task $\left[F<1, M S_{\mathrm{e}}=371, p>.10\right]$, and an interaction between orienting task and concreteness $[F(1,93)=1.43$, $\left.M S_{\mathrm{e}}=288, p>.10\right]$. Further planned comparisons revealed significant effects of concreteness for each orientingtask condition (all $p s<.05$ ). Therefore, the effect of concreteness appeared to be similar in all orienting tasks, regardless of orienting task, when context availability was confounded with concreteness.

In sum, Experiment 2 provided us with some important results for deciding among hypotheses of concreteness effects. First, when persons were forced to concentrate on retrieving prior contextual knowledge rather than imagery through rating context availability, recall differences disappeared for abstract and concrete words equated a priori on this factor. On the other hand, when persons were asked to retrieve imagery information through their ratings of imagery, the usual superiority of concrete words over abstract words resurfaced. Also, that concreteness effects in intentional recall did not differ from those in the imagery-rating task suggests that imagery may have been used by subjects to encode the lists when no particular encoding instructions were given. Therefore, the results of this experiment seem most consistent with predictions of a strategic view of concreteness effects in memory.

\section{EXPERIMENT 3}

In each of the preceding experiments, we have claimed that concreteness effects appeared in directed intentional recall for items controlled on rated context availability because subjects might be using imagery to encode the items. Thus far, the evidence for this claim has been indirect. That is, it has resied on the surface similarity of the recall patterns for the imagery orienting conditions and the overall finding of concreteness effects in undirected free recall. It is also possible that some other factor or strategy produced the concreteness effects in recall for these controlled items. The purpose of Experiment 3 was to obtain more direct evidence that the concreteness effects displayed in recall for items controlled on rated context availability can be attributed to the strategic use of imagery during encoding.

To obtain this evidence, subjects were asked to report their strategies directly following the encoding of the list. Reporting strategies directly following or during encoding has been found to be the best way to obtain veridical information regarding the strategies used during cognitive processing (Ericsson \& Simon, 1984; Fabricius \& Cavalier, 1989; Fabricius \& Hagen, 1984). To facilitate strategy report, subjects were provided with a checklist of memory strategies commonly reported in the psychological literature. The subjects could select as many strategies as applied, or they could provide their own. From this checklist, we distinguished those who selected an imagery strategy from those who did not. If an imagery strategy enables concrete words to be recalled better than abstract words even when rated context availability is controlled, then we would expect that subjects reporting strategic imagery would display concreteness effects for controlled items, whereas those not reporting it would not. On the other hand, for abstract and concrete words for which context availability is confounded with concrete- 
ness, the choice of strategy should not matter, since both the context-availability hypothesis and the strategicimagery hypothesis would predict similar results.

\section{Method}

Design. A 2 (concreteness: abstract vs. concrete) $\times 2$ (contextavailability relation: controlled vs. confounded) $\times 2$ (strategy type: reported imagery strategy or did not) design was used. Both concreteness and context availability were within-subject factors. Strategy type was a between-subject factor, and subjects were assigned on the basis of whether they reported having used an imagery strategy during the encoding of the list.

Stimuli. The stimuli were the same as those in Experiment 2, with the exception that three filler words were placed at the beginning and end of each list to reduce potential serial position effects in recall. The effectiveness of this procedure has been suggested by Christian et al. (1978). Three of these fillers were abstract and three concrete. They were the same for all four lists and not counted in the subjects' final scores.

Procedure. At the beginning of the experiment, the subjects were given the instructions used in the intentional-recall conditions of the previous two experiments. They were each handed a sheet of paper with further instructions face down. After the experimenter read the list, the subjects were told that we were really only interested in finding out what strategies they used to learn words and that they should flip over the page and check off the strategies they used to learn the words. On these sheets were the following instructions and strategies:

Below you will find a list of potential strategies that you might have used to try to help you memorize the list of words as it was being read.

Please check as many of these strategies that you remember using:

_ I tried to form mental pictures or images while the list was being read.

- I repeated each word several times to myself.

- I tried to relate each word to other things that I already knew about

(such as a context, circumstance, or some kind of general knowledge associated with each word).

_ I listened very carefully to the experimenter say the words.

- I tried to make up a story that would connect all the words together.

- I tried to categorize the words based on groups of words of simi-

lar meaning.

- I didn't do anything in particular.

- Other (please elaborate)

After they had completed filling in the strategy checklist, the subjects were told that we were also interested in finding out which strategies highly verbal people, as opposed to less verbal people, tend to use. Therefore they were asked to spend $5 \mathrm{~min}$ completing the Nelson-Denny vocabulary test for college students. However, this test was merely intended as a filler task to prevent subjects from rehearsing the list of words they had just encoded.

After the 5-min filler task was completed, the subjects were asked to recall as many of the words from the original memory list as possible by writing the items down on the piece of paper. The subjects were then debriefed and dismissed.

Subjects. The subjects were $\mathbf{8 0}$ undergraduates from an introductory psychology class who participated for course credit.

\section{Results and Discussion}

Recall scores were calculated for each subject as was done for the previous two experiments. Of the total words recalled, only $1.3 \%$ were words that could be considered synonyms, and another $12.3 \%$ were intrusions that were neither list words nor synonymous with list words. Another $25.3 \%$ of the words that subjects recalled were fillers.
To examine the influence of strategies on recall, subjects were separated according to whether they did or did not report having used imagery. Of the total number of subjects, $47.5 \%$ reported having used imagery and $52.5 \%$ did not. Most subjects (87.5\%) reported that they had flexibly used more than one strategy. All reported having done something strategic to assist recall. Of the strategies listed other than imagery, $67.6 \%$ reported rehearsal, $58.8 \%$ reported listening carefully, $38.8 \%$ had tried to categorize the words, $37.5 \%$ had attempted to form a story with the words, and $26.3 \%$ had used a context-availability strategy. Only $5 \%$ reported that they had used a strategy other than one of the strategies listed, most commonly a phonetic coding strategy.

The means for each condition of the experimental list words can be found in Table 4. To assess whether there were differential effects of concreteness as a function of whether or not subjects reported using imagery, a 2 (concreteness) $\times 2$ (context-availability relation) $\times 2$ (strategy type) ANOV A was performed. Concreteness and contextavailability relation formed within-subject variables and strategy type was a between-subject variable. This analysis yielded significant main effects of concreteness $\left[F(1,78)=30.39, M S_{c}=260\right]$, with concrete words displaying an $8.93 \%$ benefit in recall overall. There was no significant main effect of strategy type $[F(1,78)=2.71$, $M S_{\mathrm{e}}=390$ ] or of context-availability relation $(F<1$, $\left.M S_{c}=187\right)$, nor was there a significant two-way interaction between concreteness and strategy type $[F(1,78)$ $=1.86, M S_{c}=260$; all $p s>.10$ ]. There was a significant interaction between context availability and concreteness $\left[F(1,78)=6.59, M S_{c}=196, p<.05\right]$. The form of this interaction suggested a smaller concreteness effect when abstract and concrete words were controlled for context availability ( $5.9 \%$ concreteness effect) than when concreteness was confounded with context availability (13.96\% concreteness effect). Unfortunately, the three-way interaction between concreteness, contextavailability relation, and strategy type was not significant $\left[F(1,78)=1.27, M S_{\mathrm{e}}=196, p>.10\right]$.

Some statisticians suggest that overall tests of significance, such as those performed above, are not really necessary if one is only interested in examining certain contrasts (e.g., Kirk, 1982, p. 107). Instead, they suggest that it may be preferable to examine only the contrasts around which theories may have a priori predictions. Consequently, because we were interested only in testing the presence or absence of concreteness effects in

Table 4

Mean Percent Recall for Experiment 3

Relation of Context Availability to Concreteness

\begin{tabular}{lccccc}
\cline { 2 - 3 } $\begin{array}{l}\text { Strategy } \\
\text { Reported }\end{array}$ & \multicolumn{2}{c}{ Controlled } & & \multicolumn{2}{c}{ Confounded } \\
\cline { 2 - 3 } \cline { 5 - 6 } & Abstract & Concrete & & Abstract & Concrete \\
\hline No imagery & 22.1 & 23.8 & & 15.6 & 28.9 \\
Imagery & 13.5 & 23.7 & & 12.0 & 26.7 \\
\hline
\end{tabular}


specific conditions, we followed up by performing a priori nonorthogonal contrasts using Dunn's multiple-comparison procedure. These analyses yielded results more consistent with the view that concreteness effects would be found only for items controlled on rated context availability when imagery was used. When subjects did not report imagery, concreteness effects for these items were nonsignificant $(t=.56, p>.20)$. However, when they reported that they had used imagery, a significant $10.2 \%$ concreteness benefit in recall was displayed $(t=3.18, p<.05)$. Similarly, it should not matter whether subjects used imagery or not in the confounded condition, because both the strategic-imagery and the context-availability hypotheses predicted concreteness effects in this case. As predicted by both hypotheses, both subjects not reporting imagery and those reporting imagery showed significant concreteness effects in recall for confounded items $(t=4.35$ and $t=4.56$, respectively, both $p s<.05$ ).

In sum, the results of Experiment 3 followed the predictions of the strategic-imagery hypothesis. When subjects reported that they had used imagery, significant benefits of concreteness were displayed both when items were controlled on rated context availability and when they were not. However, when an imagery strategy was not reported, concreteness effects appeared in the contextavailability-confounded condition only. For these subjects, recall patterns seemed to follow context-availability ratings. In fact, subjects reporting that they had used a context-availability strategy specifically had mean recall scores nearly identical to the no-imagery group at large (concrete-controlled, 24.7\% ; abstract-controlled, 23.4\%, concrete-confounded, $28.6 \%$, and abstract-confounded, $13.0 \%$ ). Thus, it is possible that subjects not reporting imagery were using readily available information from prior knowledge to encode the words.

\section{GENERAL DISCUSSION}

These experiments enabled us to distinguish among three potential explanations for concreteness effects in verbal memory: a context-availability view, an automaticimagery view, and a strategic-imagery view. We shall examine the implications of these experiments for each hypothesis in turn.

A strict context-availability view of concreteness effects could not explain the patterns of results obtained in these experiments. If this view were correct, recall differences between abstract and concrete words should have disappeared when context availability was controlled. This prediction was not met in any experiment. In Experiment 1, when rated context availability was controlled, subjects still recalled concrete words better than abstract words. In Experiment 2, both when subjects were explicitly asked to use imagery through imagery-rating instructions and when they were able to select the information to use in directed intentional recall, concrete words were recalled better than abstract words, regardless of whether the accessibility of prior contextual knowledge was controlled for or not. In Experiment 3, when subjects reported that they had used an imagery strategy, there were clear and consistent concreteness effects.

There were, however, two cases in which subjects appeared to rely on prior contextual knowledge to remember the word lists: (1) the context-availability rating task in Experiment 2, and (2) the no-imagery condition of Experiment 3 . In these cases, recall followed the basic patterns of concreteness effects predicted by the contextavailability ratings. Of course, it might be argued that we have no explicit evidence for context-availability use in those cases, only evidence for the absence of imagery use. However, if subjects were using neither readily available information from prior knowledge nor imagery, they should have displayed similar recall across conditions because the words had been selected to be as similar as possible on other characteristics, but they did not. In both cases, concreteness effects were larger in the confounded condition than in the controlled condition. Nevertheless, together these series of experiments make clear that although recall of word lists can reflect accessibility of prior contextual knowledge, it does not always do so. Therefore, a strong claim of the context-availability hypothesis appears to be incorrect.

The findings of these experiments were also contrary to those predicted by an automatic-imagery view. This view would predict greater recall for concrete words in all conditions, regardless of the strategy used to encode them, because retrieving the meaning of a concrete word would automatically entail retrieving an image for that word along with the associated verbal information. However, in Experiment 2, when subjects were asked to perform the context-availability orienting task for items controlled a priori for context availability, subjects recalled abstract words as readily as concrete words. In Experiment 3, when subjects did not report strategically using imagery, concreteness effects were similarly absent. Thus, if subjects are directed away from using imagery, or if they choose not to use it during encoding, the potential availability of imagery or sensory information does not always result in a corresponding superiority in recall for concrete words.

The data from these experiments most closely correspond to a strategic-imagery hypothesis. This hypothesis predicts that imagery use will be independent of the availability of contextual information from prior knowledge. According to this hypothesis, persons will use imagery strategically when it is perceived to be useful in meeting the goals of a task. This strategy will be most available for highly concrete words and will mainly affect their recall. When other information seems more appropriate for the task, that information will be used instead of imagery. Evidence for this hypothesis was found in the context-availability-controlled conditions of Experiments 2 and 3 , where concreteness effects varied as a function of orienting task and strategy choice.

Previous research has yielded mixed findings regarding the influence of encoding strategies on the recall of 
abstract and concrete word lists. For example, Paivio and Csapo (1969) noted reduced concreteness effects following ratings of pronounceability as opposed to imageability ratings. On the other hand, Paivio (1975) found similar effects of pleasantness and imageability ratings on incidental recall of concrete words. Rubin (1985) also noted that free recall following imagery ratings was quite similar to recall following ratings of emotionality and orthographic distinctiveness. Berrian, Metzler, Kroll, and Clark-Meyers (1979) found no differential influence of imagery ratings over ease-of-definition and animateness ratings on recall of adjectives. Groninger and Groninger (1982) found that recall of concrete words that were defined during encoding was not significantly interfered with by later instructions to use imagery during retrieval. Both Paivio (1975) and Groninger and Groninger (1982) had suggested that the ineffectiveness of encoding context was attributable to the likely possibility that imagery occurred spontaneously for concrete words despite the encoding task. The present experiments make clear, however, that when imageability and context availability are highly correlated, it is fairly difficult to discern an independent influence of imagery. It is very likely that the concrete words used in the previous studies were both highly imageable and relatively easy to retrieve prior contextual knowledge for, thereby enabling superior recall of concrete words regardless of the encoding task used. The present experiments, by distinguishing effects attributable to the accessibility of prior knowledge from those attributable to imagery, were able to show an independent influence of imagery beyond other factors.

The findings of these experiments also appear to contradict those of a number of recent studies showing that concreteness effects in comprehension and memory disappear when the verbal materials are presented in a wellsupporting context (Marschark, 1985; Schwanenflugel et al., 1988; Schwanenflugel \& Shoben, 1983; Schwanenflugel \& Stowe, 1989; Wattenmaker \& Shoben, 1987). In particular, whereas Schwanenflugel et al. (1988) found that lexical decisions for abstract and concrete words did not differ when rated context availability was controlled. Recall for the same words in the present experiments did display a superiority for concrete words over abstract words in some cases. Thus, it cannot be assumed that recall of abstract and concrete words will be a direct reflection of their initial ease of processing.

One way to reconcile these apparently discrepant findings would be to assume that persons usually use highly available information to perform a task, but that they use imagery strategically when the most available information is seen as insufficient for meeting task goals. When persons are making lexical decisions or reading for comprehension with simple aims, retrieving the most available information from prior knowledge may be seen as adequate to support the process. Similarly, if a person is reading a coherent text for later recall, perhaps the amount of supportive information that the person can retrieve from prior knowledge is sufficient for successful task comple- tion. On the other hand, if a person is given a list of unrelated words or a series of unrelated sentences to recall, this may be seen as a difficult task for which calling on imaginal information might help beyond the simple retrieval of prior knowledge (see Marschark, 1985). Similarly, for verifying certain kinds of concrete sentences where the information needed for verification cannot readily be retrieved from prior knowledge, persons might find it beneficial to form imagery to perform the task (Glass, Eddy, \& Schwanenflugel, 1980; Glass, Millen, Beck, \& Eddy, 1985; Kosslyn, 1980). This position is bolstered by Experiment 3, in which subjects who did not see the need to employ imagery strategically showed recall in the manner predicted by the simple availability of information from prior knowledge. Therefore, it is possible that imagery is used strategically only when prior contextual knowledge does not seem sufficient to enable task performance.

These experiments may also tell us something about the nature of abstract and concrete word concepts in general. Recent discussions of the characteristics of concept representations display a clear movement away from thinking of concepts as having static representations and toward emphasizing the contextual, goal-oriented nature of concepts (Barsalou, 1983, 1985; Barsalou \& Medin, 1986; Greenspan, 1986). One aspect of this view of concepts is that persons are highly flexible with regard to the information that is retrieved for a given concept in a given circumstance. According to this view, not all the aspects of the representation of a particular concept are retrieved as a whole when that concept is used. In particular, concept attributes that meet the present goal for using the concept are more likely to be retrieved than those that are not. Moreover, some attributes may only be retrievable in certain contexts. For example, if one has the goal of finding something to throw to a drowning person, one might retrieve the attribute "floats" for basketball, although the feature might never come to mind otherwise. In the present experiments, with the goal of remembering a list of unrelated words, subjects might retrieve and focus on the attributes that assist in imaging. However, if subjects are given other goals, such as rapid comprehension, they might rely on only the most readily available information. Thus, the present studies support this view of concept representations, by showing that although the aspects of concepts that enable imagery are not always retrieved in processing, they are sometimes retrieved to meet the goals of tasks.

In sum, the present experiments have demonstrated an effect of imagery independent of the availability of prior contextual knowledge in memory for lists of abstract and concrete words. These results have been discussed as supporting a strategic-imagery view of concreteness effects. While some suggestions have been made with regard to the likely conditions for employing imagery beyond other kinds of contextual knowledge, further research will be needed to define the boundary conditions for using the various kinds of information associated with abstract and 
concrete concepts. In any case, the present experiments make clear that neither a strong imagery view nor a simple context-availability view of concreteness effects in verbal recall is correct.

\section{REFERENCES}

Barsalou, L. W. (1983). Ad hoc categories. Memory \& Cognition, 11, 211-227.

BARSALOU, L. W. (1985). Ideals, central tendency, and frequency of instantiation as determinants of graded structure in categories. Journal of Experimental Psychology: Learning, Memory, \& Cognition, 11, 629-654.

Barsalou, L. W., Medin, D. L. (1986). Concepts: Static definitions or context-dependent representations? Cahiers de Psychologie Cognitive, 6, 187-202.

Berrian, R. W., Metzler, D. P., Kroll, N. E. A., \& Clark-Meyers, G. M. (1979). Estimates of imagery, ease of definition, and animateness for 328 adjectives. Journal of Experimental Psychology: Human Learning \& Memory, 5, 435-447.

Bransford, J. D., \& MCCARrell, N. S. (1974). A sketch of a cognitive approach to comprehension: Some thoughts on what it means to comprehend. In W. Weimer \& D. Palermo (Eds.), Cognition and the symbolic processes (pp. 189-230). Hillsdale, NJ: Erlbaum.

BREWER, W. F. (1975), Memory for ideas: Synonym substitution. Memory \& Cognition, 3, 458-464.

Brown, J. I., BennetT, J. M., \& Hanna, G. (1981). The Nelson-Denny Reading Test (Form E). Lombard, IL: Riverside.

Christian, J., Bickley, W., TARka, M., \& Clayton, K. (1978). Measures of free recall of 900 English nouns: Correlations with imagery, concreteness, meaningfulness, and frequency. Memory \& Cognition, 6. 379-390.

Ericsson, K. A., \&imon, M. A. (1984). Protocol analysis: Verbal reports as data. Cambridge, MA: MIT Press.

Fabricius, W. V., \& CAvalier, L. (1989). The role of causal theories about memory in young children's strategy choice. Child Development, 60, 298-308.

Fabricius, W. V., Hagen, J. W. (1984). The use of causal attributions about recall performance to assess metamemory and predict strategic memory behavior in young children. Developmental Psychology, 20, 975-987.

FrANCIS, W. N., \& KuČERA, H. (1982). Frequency analysis of English usage: Lexicon and grammar. Boston: Houghton Mifflin.

Glass, A. L., Eddy, J. K., \& Schwanenflugel, P. J. (1980). The verification of high and low imagery sentences. Journal of Experimental Psychology: Human Learning \& Memory, 6, 692-704.

Glass, A. L., Millen, D. R., Beck, L. G., Eddy, J. K. (1985). Representation of images in sentence verification. Joumal of Memory \& Language, 24, 442-465.

GreENSPAN, S. L. (1986). Semantic flexibility and referential specificity of concrete nouns. Journal of Memory \& Language, 25, 539-557.

Groninger, L. D., Groninger, L. K. (1982). Function of images during the encoding-retrieval process. Journal of Experimental Psychology: Learning, Memory, \& Cognition, 8, 353-358.

KIERAS, D. (1978). Beyond pictures and words: Alternative information processing models for imagery effects in verbal memory. Psychological Bulletin, 85, 532-554.

KIRK, R. E. (1982). Experimental design: Procedures for the behavioral sciences. Belmont, CA: Brooks/Cole.
Kosslyn, S. M. (1980). Image and mind. Cambridge, MA: Harvard University Press.

MARSCHARK, M. (1985). Imagery and organization in the recall of high and low imagery prose. Joumal of Memory \& Language, 24, 734-745.

Marschark, M., \& Paivio, A. (1977). Integrative processing of concrete and abstract sentences. Joumal of Verbal Learning \& Verbal Behavior, 16, 217-231.

NAGY, W. E., ANDERSON, R. C. (1984). How many words are there in printed school English? Reading Research Quarterly, 19, 304-330.

Palvio, A. (1965). Abstractness, imagery, and meaningfulness in paired associate learning. Journal of Verbal Learning \& Verbal Behavior, 4, 32-38.

Paivio, A. (1971). Imagery and verbal processes. New York: Holt, Rinehart \& Winston.

Palvio, A. (1975). Coding distinctions and repetition effects in memory In G. H. Bower (Ed.), The psychology of learning and motivation: Advances in research and theory (Vol. 9, pp. 179-215). New York: Academic Press.

PAIVIO, A. (1986). Mental representations: A dual-coding approach. Oxford: Oxford University Press.

Paivio, A., \& CsAPo, K. (1969). Concrete-image and verbal memory codes. Journal of Experimental Psychology, 80, 279-285.

Paivio, A., Yullle, J. D., Madigan, S. A. (1968). Concreteness, imagery, and meaningfulness values for 925 nouns. Joumal of $E x$ perimental Psychology Monographs, 76(1, Pt. 2), 1-25.

Peterson, R. (1974). Imagery and cued recall: Concreteness or context? Journal of Experimental Psychology, 102, 841-844.

RuBin, D. C. (1980). 51 properties of 125 words: A unit of analysis of verbal behavior. Journal of Verbal Learning \& Verbal Behavior, 19, 736-755.

RuBIN, D. C. (1983). Associative asymmetry, availability, and retrieval. Memory \& Cognition, 11, 83-92.

RUBIN, D. C. (1985). Memorability as a measure of processing: A unit of analysis of prose and list learning. Journal of Experimental Psychology, 114, 213-238.

Rubin, D. C., * Friendly, M. (1986). Predicting which words get recalled: Measures of free recall, availability, goodness, emotionality, and pronunciability for 925 nouns. Memory \& Cognition, 14, 79-94.

SChWANENflugel, P. J. (1991). Why are abstract concepts hard to understand? In P. J. Schwanenflugel (Ed.), The psychology of word meanings (pp. 223-250). Hillsdale, NJ: Erlbaum.

Schwanenflugel, P. J., Harnishfeger, K. K., Stowe, R. W. (1988). Context availability and lexical decisions for abstract and concrete words. Joumal of Memory \& Language, 27, 499-520.

Schwanenflugel, P. J., \& Shoben, E. J. (1983). Differential context effects in the comprehension of abstract and concrete verbal materials. Joumal of Experimental Psychology: Learning, Memory, \& Cognition, 9, 82-102.

SChWanenflugel, P. J., \& Stowe, R. W. (1989). Context availability and the processing of abstract and concrete words in sentences. Reading Research Quarterly, 24, 114-126.

Vellutino, F. R., SCanlon, D. M. (1985). Free recall of concrete and abstract words in poor and normal readers. Joumal of Experimental Child Psychology, 39, 363-380.

Wattenmaker, W. D., Shoben, E. J. (1987). Context and the recallability of concrete and abstract sentences. Journal of Experimental Psychology: Learning, Memory, \& Cognition, 13, 140-150.

(Manuscript received August 23, 1988; revision accepted for publication July 26,1991 .) 